\title{
ANALISIS JENIS DAN KAIDAH KEBAHASAAN TEKS PERSUASIF PADA KUMPULAN MOTIVASI MERRY RIANA
}

\author{
Ida Ayu Candra Dewi \\ Prodi Pendidikan Bahasa Pascasarjana \\ Universitas Pendidikan Ganesha \\ Singaraja, Indonesia \\ e-mail: dayucandra06@yahoo.com
}

\begin{abstract}
Abstrak
Tujuan penelitian ini adalah (1) menemukan jenis persuasif yang terdapat dalam kumpulan motiasi Merry Riana. (2) mendeskripsikan kaidah kebahasaan yang terdapat dalam kumpulan motivasi Merry Riana. Jenis penelitian ini adalah penelitian kualitatif yang bersifat deskriptif dengan objek penelitian kumpulan motivasi Merry Riana pada media social instagram. Data penelitian ini berupa kutipan-kutipan motivasi dari Merry Riana yang di sebarkan di media social instagram. Teknik pengumpulan data menggunakan teknik simak dan catat dengan teknik lanjutan teknik simak bebas libat cakap. Analisis data dalam penelitian ini menggunakan metode padan dengan teknik lanjutan pilah unsur penentu. Berdasarkan hasil penelitian dapat disimpulkan, bahwa dalam kumpulan Motivasi Merry Riana terdapat dua jenis persuasif yang digunakan yaitu jenis persuasif propaganda dan persuasif pendidikan. Sedangkan kaidah kebahasaan yang terdapat dalam kumpulan motivasi Merry Riana ada tiga yaitu kaidah kebahasaan kata bujukan, kata kerja imperatif, dan kata penghubung argumentatif. Jenis persuasif yang sering digunakan adalah jenis persuasif propaganda dan kaidah kebahasaan yang sering digunakan dalam motivasi Merry Riana adalah kaidah kebahasaan kata penghubung argumentatif.
\end{abstract}

Kata kunci : Persuasi, Motivasi, Jenis Persuasi, Kaidah Kebahasaan

\section{Abstract}

The purpose of this study was (1) to find the type of persuasion found in the collection of Merry Riana's motivations. (2) describe the language rules contained in Merry Riana's motivational collection. This type of research is descriptive qualitative research with the object of Merry Riana's motivation collection research on Instagram social media. This research data is in the form of motivational quotes from Merry Riana which are distributed on Instagram social media. The technique of collecting data uses the referring technique and records it with advanced skillful techniques for referring to free engagement. Analysis of the data in this study uses the equivalent method with advanced techniques to sort the determinant elements. Based on the results of the study it can be concluded, that in the Merry Riana Motivation collection there are two types of persuasiveness used, namely the type of persuasive propaganda and persuasive education. While the linguistic rules contained in Merry Riana's motivational collection are three, namely linguistic rules of persuasion, imperative verbs, and argumentative conjunctions. The persuasive type that is often used is the type of persuasive propaganda and linguistic rules that are often used in Merry Riana's motivation are the rules of argumentative language norms.

Keywords : Persuasion, Motivation, Type of Persuasion, Linguistic Rules 


\section{PENDAHULUAN}

Motivasi mempunyai peranan yang strategis dalam aktivitas belajar seseorang. Tidak ada seorang pun yang belajar tanpa motivasi. Motivasi belajar merupakan salah satu faktor yang turut menentukan keefektifan dalam pembelajaran. Seorang peserta didik akan belajar dengan baik apabila ada faktor pendorongnya yaitu motivasi belajar. Peserta didik akan belajar dengan sungguh-sungguh jika memiliki motivasi belajar yang tinggi. Motivasi belajar adalah seluruh daya penggerak di dalam diri siswa yang menimbulkan kegiatan belajar yang menjamin kelangsungan dari kegiatan belajar yang memberikan arah pada kegiatan belajar sehingga tujuan yang dikehendaki oleh subjek belajar itu dapat dicapai (Sardiman A. M, 2007: 75). Menurut Emda (2017) Motivasi belajar dapat diklasifikasikan menjadi dua yaitu motivasi instrinsik (keadaan keadaan yang berasal dari dalam diri siswa sendiri yang dapat mendorongnya melakukan tindakan belajar) dan motivasi ekstrinsik (keadaan yang datang dari luar individu siswa yang mendorongnya untuk melakukan kegiatan belajar). Ada tidaknya motivasi belajar sangat mempengaruhi keberhasilan belajar siswa.

Menurut Fauzah dkk (2017) Motivasi merupakan dorongan seseorang secara sadar atau tidak sadar untuk melakukan sesuatu kegiatan untuk mencapai tujuannya. Motivasi juga bisa berasal dari dalam diri dan dari orang lain, baik itu guru, keluarga dan teman. Menurut Waruwu (2017) Motivasi muncul dari dalam diri manusia, tetapi keberadaannya karena rangsangan atau dorongan oleh adanya unsur lain, dalam hal ini adalah dorongan untuk mencapai tujuan. Menurut Saptono (2016) Motivasi adalah suatu kekuatan atau tenaga pendorong untuk melakukan sesuatu hal atau menampilkan suatu perilaku tertentu. Motivasi merupakan masalah sentral dalam dunia psikologi. Saat guru berdiri dalam kelas dan memulai bercerita kepada murid-murid tentang mata pelajaran, tentunya guru berharap murid antusias dengan pelajaran yang diterangkannya. Guru menatap mata siswa satu persatu dan memperkirakan kemampuan mereka dalam menangkap bahan pelajaran yang diberikan. Kegiatan tersebut merupakan salah satu pemberian motivasi kepada siswanya. Motivasi merupakan inti dari sifat biologis, kognitif, dan aturan- aturan sosial. Individu akan termotivasi karena mereka dapat menilai suatu kegiatan, atau adanya paksaan yang kuat dari luar.
Ada banyak faktor yang mempengaruhi motivasi belajar yang dapat dibedakan menjadi dua faktor. Menurut Syamsu Yusuf (2009: 23) motivasi belajar dapat timbul karena faktor internal dan eksternal. Faktor internal yang mempengaruhi motivasi belajar yaitu: (1) Faktor Fisik meliputi nutrisi (gisi), kesehatan, dan fungsi-fungsi fisik (terutama panca indera), (2) Faktor Psikologis, yaitu berhubungan dengan aspek-aspek yang mendorong atau menghambat aktivitas belajar pada siswa. Faktor eksternal (yang berasal dari lingkungan) yang mempengaruhi motivasi belajar meliputi: (1) Faktor Non-Sosial meliputi keadaan udara (cuaca panas atau dingin), waktu (pagi, siang, malam), tempat (sepi, bising, atau kualitas sekolah tempat belajar), sarana dan 2 prasarana atau fasilitas belajar, (2) Faktor Sosial, merupakan faktor manusia (guru, konselor, dan orang tua). Sehubungan dengan faktor-faktor tersebut, guru sangat berperan dalam meningkatkan motivasi belajar. Karena dari hasil pengamatan bahwa pada saat kegiatan pembelajaran berlangsung ada sekitar 5 siswa yang tidak memperhatikan dan ribut sendiri di dalam kelas. Oleh karena itu, guru harus mampu menciptakan pembelajaran yang menarik dan menyenangkan agar siswa memiliki motivasi belajar yang tinggi. Agar siswa termotivasi dan merasa senang dalam mengikuti pembelajaran maka, sangat diperlukan keterampilanketerampilan guru dalam mengajar sesuai dengan perkembangan zaman dan kemajuan teknologi. Keterampilan-keterampilan yang perlu dikuasai oleh guru antara lain keterampilan bertanya dasar, keterampilan bertanya lanjut, keterampilan memberi penguatan (reinforcemen), keterampilan mengadakan variasi, keterampilan menjelaskan, keterampilan membuka dan menutup pelajaran, keterampilan mengelola kelas, keterampilan memimpin diskusi kelompok kecil, keterampilan mengajar kelompok kecil dan perorangan (Syaiful Bahri Djamarah, 2005: 99-163). Penggunaan alat bantu pembelajaran dan pengetahuan cara mengajar yang menarik termasuk dalam keterampilan mengadakan variasi agar dapat menimbulkan sikap positif dan meningkatkan motivasi belajar dalam diri siswa.

Di dalam motivasi pasti terdapat unsur-unsur persuasif yang membuat seseorang tertarik untuk melakukan hal yang terdapat di dalam kata- kata motivasi tersebut. Salah satu kata-kata motivasi yang sangat terkenal dikalangan anak muda atau remaja adalah kata motivasi dari Merry Riana. Merry Riana adalah salah satu tokoh motivator yang 
sangat terkenal dan memiliki banyak kata-kata yang menginspirasi banyak khalayak khususnya anak muda. Motivasi Merry Riana sering dijadikan motivasi atau di muat kembali oleh anak muda pada media sosial mereka. Kata-kata dalam motivasi Merry Riana sangat bernaneka ragam, ada motivasi kehidupan, sahabat, pendidikan, maupun tentang cinta. Hal tersebutlah yang membuat anak muda tertarik dengan motivasi yang sering dimuat oleh Merry Riana. Dalam motivasi Merry Riana juga terdapat nilai-nilai, misalnya nilai pendidikan, nilai soial, nilai religius, dan nilai moral.

Berdasarkan hal tersebutlah yang membuat peneliti tertarik dalam meneliti motivasi Merry Riana dan dijadikan materi pengantar pembelajaran Bahasa Indonesia di SMA. Motivasi sangat penting jika dijadikan sebagai materi pembelajaran, karena motivasi langsung mengarah pada kehidupan dan siswa secara langsung akan dapat mempelajari makna dari kehidupan melalui motivasi.

\section{METODE}

Dalam penelitian ini, peneliti menggunakan rancangan deskriptif dengan menggunakan metode kualitatif. Tujuan penelitian deskriptif kualitatif ini adalah menggambarkan secara sistematis, faktual dan akurat mengenai fakta dan karakteristik objek dan subjek yang diteliti secara tepat. Penelitian deskriptif kualitatif digunakan untuk mendeskripsikan data yang berkaitan dengan persuasif dalam motivasi Merry Riana. Penggunaan metode penelitian deskriptif kualitatif pada penelitian ini adalah untuk menggambarkan data sesuai dengan kondisi sebenarnya.

Subjek penelitian adalah orang yang dikenai tindakan (Wendra, 2009:53). Lebih lanjut Suandi (2008:31) berpendapat subjek penelitian adalah benda, hal, atau orang tempat variable melekat, dan yang dipermasalahkan dalam penelitian. Subjek penelitian ini adalah kumpulan motivasi Merry Riana.

Selanjutnya, objek penelitian adalah masalah yang hendak dikaji (Wendra, 2009:45). Sejalan dengan konsep tersebut, objek penelitian ini seperti tampak pada masalah yang diajukan, yaitu bentuk persuasif, nilai kehidupan dalam motivasi, serta manfaat motivasi bagi pembelajaran.

Dalam sebuah penelitian data yang akan dianalisis tentunya harus dikumpulkan dengan menggunakan metode yang tepat.
Sesuai dengan karakteristik data, metode pengumpulan data yang digunakan dalam penelitian ini adalah metode dokumentasi dengan teknik baca catat.

Dalam metode dokumentasi, peneliti melakukan pengumpulan, pengolahan, dan penyampaian informasi dalam bidang pengetahuan; pemberian atau bukti keterangan (seperti gambar, kutipan, kliping, koran, dan referensi lain). Studi documenter merupakan studi teknik pengumpulan data dengan menghimpun dan menganalisis dokumen-dokumen, baik dokumen tertulis, gambar, maupun dokumen elektronik.

Metode dokumentasi dengan teknik baca catat merupakan metode pengumpulan data yang paling tepat digunakan dalam penelitian ini. Hal tersebut dikarenakan data penelitian ini berupa dokumen tertulis. Hal pertama yang dilakukan dalam proses pengumpulan data penelitian ini adalah membaca secara cermat setiap cerpen yang sudah terkumpul. Pembacaan data secara cermat ini bertujuan untuk mengumpulkan bentuk persuasif yang digunakan pada motivasi Merry Riana. Hal yang dilakukan selanjutnya adalah mencatat data yang sudah dibaca ke dalam kartu data yang sudah disiapkan. Untuk mengumpulkan data masalah (1) digunakan metode dokumentasi dengan teknik baca catat dan masalah (2) menggunakan metode dokumentasi dengan teknik baca catat.

Dalam penelitian ini, peneliti menggunakan teknik analisis data deskriptif kualitatif. Teknik analisis data deskriptif kualitatif adalah suatu teknik menganalisis data dengan cara menginterpretasikan data yang diperoleh dengan kata-kata.

\section{HASIL DAN PEMBAHASAN}

Hasil penelitian ini mencakup (1) jenis persuasif yang terdapat dalam kumpulan motivasi Merry Riana (2) kaidah kebahasaan teks persuasif yang terdapat dalam kumpulan motivasi Merry Riana.

Dalam penelitian ini, penulis memilih dua puluh kumpuluan motivasi Merry Riana yang terdapat di media social Instagram sebagai sumber data. Hal tersebut didasarkan atas beberapa alasan yang telah dikemukakan pada latar belakang penelitian ini. Kedua puluh data tersebut didata dan diberi nomor data.

Data berupa jenis persuasif dan kaidah kebahasaan teks persuasif yang terdapat dalam kumpulan motivasi Merry Riana, dicatat di dalam kartu data tanpa disertai pemaparan lebih terperinci mengenai 
jenis persuasif dan kaidah kebahasaan teks persuasif yang terdapat pada data tersebut. Hal ini dilakukan agar analisis data lebih efektif dan efisien. Pemaparan lebih rinci mengenai kedua hal tersebut dituangkan dalam hasil penelitian.

Untuk memudahkan dalam pengecekan dan pemaparan hasil penelitian, dalam setiap kartu data juga dicantumkan nomor data serta kutipan masing-masing motivasi yang terdapat pada data tersebut. Data-data yang dianalisis dalam penelitian ini berupa penggalan kalimat, kalimat, serta kumpulan kalimat (paragraf). Hal ini dikarenakan analisis jenis persuasif dan kaidah kebahasaan teks persuasif terkadang tidak dapat dilakukan dalam sebuah kalimat tetapi harus dikaitkan dengan kalimat-kalimat lain serta tidak mengabaikan konteks agar mendapatkan hasil analisis yang lebih tepat.

\section{A. Jenis Persuasif yang terdapat dalam Kumpulan Motivasi Merry Riana}

Jenis persuasif yang dianalisis dalam penelitian ini mencakup analisis keseluruhan jenis persuasif yang terdiri atas persuasi politik, persuasi pendidikan, persuasi advertensi, dan persuasi propaganda. Hasil analisis jenis persuasif dalam kumpulan motivasi Merry Riana adalah sebagai berikut.

"BANYAK PEMIMPI BESAR YANG AWALNYA DITERTAWAKAN SAMPAI DISEBUT GILA. SEMUA AKHIRNYA BUNGKAM SETELAH MELIHAT MIMPI MEREKA MENJADI KENYATAAN" (Data Nomor 1)

(Sumber data : Instagram @merryriana)

Kutipan motivasi di atas bermakna banyak manusia yang sering meremehkan mimpi-mimpi yang tinggi yang dimiliki oleh rekan mereka, seolah-olah mimpi atau keinginan tersebut tidak bisa dicapai atau diwujudkan. Namun, ketika mimpi itu dapat diwujudkan oleh mereka yang memiliki mimpi yang tinggi, maka orang yang sebelumnya meremehkan mereka tidak akan bisa berkata tentang apapun, karena mimpi mereka telah menjadi kenyataan. Dari makna tersebut dapat dilihat bahwa kutipan motivasi di atas termasuk dalam jenis persuasif pendidikan yang mengarah pada cara mendidik karakter seseorang agar lebih baik dalam berucap dan berpikir terhadap orang lain.
"HADAPI SEGALA RINTANGAN, DAN JANGAN PERNAH HILANG HARAPAN. KARENA KETIKA KAMU MASIH MEMILIKI HARAPAN, DISITULAH KAMU MEMILIKI MASA DEPAN" (Data Nomor 2)

(Sumber data : Instagram @merryriana)

Kutipan motivasi di atas bermakna jangan pernah menyerah menghadapi rintangan dan jangan mudah putus asa, karena jika melakukan semua itu semua harapan yang di miliki tidak akan dapat terwujud. Namun, jika semua itu tidak dilakukan masa depan yang indah akan menanti. Dari makna tersebut kutipan motivasi di atas termasuk jenis persuasi propaganda, karena memberikan sebuah informasi agar seseorang tidak mudah untuk berhenti berharap dan berusaha. Lebih dari itu, dengan informasi diharapkan pembaca mau dan sadar untuk berbuat sesuatu.

"MUDA ITU TIDAK DITENTUKAN OLEH UMUR DAN FISIK YANG PENTING SEMANGAT UNTUK SELALU MELAKUKAN YANG TERBAIK. KRITIS DENGAN CARA YANG KREATIF, POSITIF DAN JUGA ASYIK" (Data Nomor 3)

(Sumber data : Instagram @merryriana)

Kutipan motivasi di atas bermakna bahwa umur dan fisik bukanlah penentu segalanya, yang terpenting dalam hidup ini adalah semangat untuk menjalani kehidupan dan hidup sebagai manusia yang kreatif dan positif. Dari makna kutipan tersebut dapat dilihat bahwa terdapat jenis persuasif propaganda, karena adanya informasi yang memberikan semangat bagi pembaca agar dalam menjalani hidup jangan hanya berpatokan pada umur dan fisik.

"JANGAN HANYA BUAT RESOLUSI, TAPI JUGA NIAT UNTUK MENJALANINYA. KAMU HARUSNYA SEPERTI PERANGKO, YANG NEMPEL TERUS SAMPAI DI TUJUAN. KAMU HARUSNYA MASA BODO, LUPAKAN SEMUA KETAKUTAN DAN KEKHAWATIRAN" (data nomor 4)

(Sumber data : Instagram @merryriana)

Kutipan motivasi di atas bermakna dalam hidup jangan hanya membuat ketetapan atau rencana. Jika niat untuk mewujudkan atau menjalaninya tidak ada maka semua itu akan percuma. Resolusi akan tercapai apabila 
terus fokus tanpa mengahiraukan orang-orang yang ingin membatalkan resolusi yang telah dibuat. Dari makna tersebut jenis persuasif yang terdapat pada kutipan motivasi di atas adalah persuasi propaganda, karena memberikan informasi tentang ajakan agar pembaca mau dan sadar untuk berbuat sesuatu.

"HATIMU HARUS TETAP KUAT, DAN PERCAYALAH KESEMPATAN SELALU DATANG KEPADA ORANG YANG NIAT. APAPUN YANG TERJADI KAMU HARUS TETAP BERTAHAN, DAN SELALU INGAT UNTUK SELALU SERTAKAN TUHAN" (data nomor 5)

(Sumber data : Instagram @merryriana)

Kutipan motivasi di atas bermakna harus kuat dalam menghadapi rintanganrintangan, dan jangan mudah putus asa jika kegagalan menghampiri karena kesempatan akan selalu datang lagi apabila niat masih ada. Dari makna tersebut, kutipan motivasi di atas termasuk jenis persuasif pendidikan, karena di saat seseorang membaca motivasi di atas, akan merasakan di didik untuk tetap kuat, tetap bertahan, dan selalu ingat dengan Tuhan dalam setiap langkah. Jenis persuasif pendidikan ini juga dapat memengaruhi anak didik agar lebih giat dalam belajar dan selalu menggunakan kesempatan yang baik untuk mengembangkan diri sebagai pelajar.

\section{B. Kaidah Kebahasaan yang terdapat dalam Kumpulan Motivasi Merry Riana}

Kaidah Kebahasaan yang dianalisis dalam penelitian ini mencakup analisis keseluruhan kaidah kebahasaan teks persuasif yang terdiri atas kata bujukan, kata kerja imperative, kata-kata teknis atau peristilahan yang berkenaan dengan topik, dan kata penghubung yang argumentatif. Hasil analisis kaidah kebahasaan dalam kumpulan motivasi Merry Riana adalah sebagai berikut.

\section{"BANYAK PEMIMPI BESAR YANG AWALNYA DITERTAWAKAN SAMPAI DISEBUT GILA. SEMUA AKHIRNYA BUNGKAM SETELAH MELIHAT MIMPI MEREKA MENJADI KENYATAAN" (Data Nomor 1)}

(Sumber data : Instagram @merryriana)

Kutipan motivasi di atas memakai kaidah kebahasaan penghubung yang argumentatif, karena terdapat unsur sebab akibat di dalam kutipan motivasi tersebut. Sebab akibat adalah bagian dari penghubung argumentatif. Penghubung Sebab ditunjukan oleh kutipan "BANYAK PEMIMPI BESAR YANG AWALNYA DITERTAWAKAN" dan penghubung Akibat ditunjukkan oleh kutipan "SEMUA AKHIRNYA BUNGKAM SETELAH MELIHAT MIMPI MEREKA MENJADI KENYATAAN"

"HADAPI SEGALA RINTANGAN, DAN JANGAN PERNAH HILANG HARAPAN. KARENA KETIKA KAMU MASIH MEMILIKI HARAPAN, DISITULAH KAMU MEMILIKI MASA DEPAN" (Data Nomor 2)

(Sumber data : Instagram @merryriana)

Kutipan motivasi di atas memakai kaidah kebahasaan kata penghubung yang argumentatif. Kaidah kebahasaan itu ditunjukkan oleh penggunaan kata karena pada kutipan "KARENA KETIKA KAMU MASIH MEMILIKI HARAPAN" katakarena termasuk dalam kata penghubung argumentative

"MUDA ITU TIDAK DITENTUKAN OLEH UMUR DAN FISIK YANG PENTING SEMANGAT UNTUK SELALU MELAKUKAN YANG TERBAIK. KRITIS DENGAN CARA YANG KREATIF, POSITIF DAN JUGA ASYIK" (Data Nomor 3)

(Sumber data : Instagram @merryriana)

Kutipan motivasi di atas memakai kaidah kebahasaan kata bujukan, hal tersebut ditunjukkan oleh kumpulan kata-kata motivasi yang digunakan pada motivasi di atas yakni keharusan untuk tetap semangat melakukan yang terbaik.

"JANGAN HANYA BUAT RESOLUSI, TAPI JUGA NIAT UNTUK MENJALANINYA. KAMU HARUSNYA SEPERTI PERANGKO, YANG NEMPEL TERUS SAMPAI DI TUJUAN. KAMU HARUSNYA MASA BODO, LUPAKAN SEMUA KETAKUTAN DAN KEKHAWATIRAN" (data nomor 4)

(Sumber data : Instagram @merryriana)

Kutipan motivasi di atas memakai kaidah kebahasaan kata bujukan, hal tersebut ditunjukkan oleh kata "harusnnya" pada kutipan "kamu harusnya seperti perangko" yang berarti membujuk agar melakukan hal 
seperti yang dikatakan dalam motivasi tersebut.

"HATIMU HARUS TETAP KUAT, DAN PERCAYALAH KESEMPATAN SELALU DATANG KEPADA ORANG YANG NIAT. APAPUN YANG TERJADI KAMU HARUS TETAP BERTAHAN, DAN SELALU INGAT UNTUK SELALU SERTAKAN TUHAN" (data nomor 5)

(Sumber data : Instagram @merryriana)

Kutipan motivasi di atas memakai kaidah kebahasaan kata bujukan, hal tersebut ditunjukkan oleh kata "harus" pada kutipan "hatimu harus kuat" yang berarti membujuk untuk tetap menguatkan hati dalam keadaan apapun. Kata "harus" merupakan bagian dari kata bujukan

"SESULIT APAPUN SITUASI KAMU PADA SAAT INI, SEBERAT APAPUN COBAAN ITU. SADARLAH, SELAMA KAMU MASIH HIDUP, ITU ARTINYA TUHAN MASIH SAYANG SAMA KAMU. BERTERIMAKASIHLAH, KARENA TIDAK SEMUA ORANG DIBERI KESEMPATAN ITU" (data nomor 6)

(Sumber data : Instagram @merryriana)

Kutipan motivasi di atas memakai kaidah kebahasaan kata penghubung argumentatif, hal tersebut dapat dilihat dari penggunaan kata "karena" pada kutipan "karena tidak semua orang diberi kesempatan itu" kata "karena " merupakan bagian dari kata penghubung argumentative, yang menjelaskan pendapat mengenai alasan tentang sesuatu ayang terjadi.

"SEPERTI APA KITA DILAHIRKAN ADALAH TAKDIR. SEPERTI APA KITA BERTUMBUH ADALAH PROSES. SEPERTI APA KITA DI HARI TUA ADALAH KEPUTUSAN" (data nomor 7)

(Sumber data : Instagram @merryriana)

\footnotetext{
Kutipan motivasi di atas memakai kaidah kebahasaan kata penghubung argumentatif, hal tersebut dapat dilihat dari kata "seperti" pada kutipan "seperti apa kita bertumbuh adalah proses. Seperti apa kita di hari tua adalah keputusan" kata "seperti" termasuk jenis kata penghubung argumentative yaitu pendapat untuk mengandaikan suatu hal.
}

"MINTA MAAF TIDAK SELALU BERARTI KITA SALAH. ITU BISA BERARTI KITA LEBIH MENGHARGAI CINTA DAN PERSAHABATAN DI ATAS EGO KITA" (data nomor 8)

(Sumber data : Instagram @merryriana)

Kutipan motivasi di atas memakai kaidah kebahasaan kata bujukan hal tersebut dapat dilihat dari penggalan kalimat yang digunakan dalam motivasi tersebut adalah untuk membujuk seseorang, untuk melakukan hal yang lebih baik.

"PERLIHATKAN KEMAMPUAN KITA, BUKAN HANYA LEWAT KATA-KATA DAN JANJI-JANJI SAJA, TAPI JUGA MELALUI HASIL TINDAKAN NYATA" (data nomor 9)

(Sumber data : Instagram @merryriana)

Kutipan motivasi di atas memakai kaidah kebahasaan kata kerja imperative, kata kerja imperative digunakan untuk memberi perintah, larangan, dan instruksi. Hal tersebut dapat dillihat dari penggalan kalimat motivasi di atas berupa instruksi yang harus dilaksanakan dan dilakukan.

Pembahasan pada penelitian ini berdasarkan rumusan masalah yang telah dikaji oleh peneliti sebelumnya. Berdasarkan data yang telah diperoleh dan kemudian dianalisis, peneliti mendapatkan jenis persuasif dan kaidah kebahasaan pada kutipan motivasi Merry Riana. (1) Jenis persuasif yang digunakan pada kutipan motivasi Merry Riana menggunakan dua jenis persuasif yaitu persuasif propaganda dan persuasif pendidikan. Menurut teori yang disampaikan oleh Sumirat \& Suryana (2014 :2.25) menyatakan persuasif pendidikan dipakai oleh orang-orang yang berkecimpung dalam bidang pendidikan dan digunakan untuk mencapai tujuan-tujuan pendidikan. Berikut adalah salah satu contoh motivasi yang berjenis persuasif pendidikan.

"MINTA MAAF TIDAK SELALU BERARTI KITA SALAH. ITU BISA BERARTI KITA LEBIH MENGHARGAI CINTA DAN PERSAHABATAN DI ATAS EGO KITA"

Kutipan motivasi di atas merupakan motivasi yang mengandung jenis persuasif pendidikan. Minta maaf merupakan bagian dari mendidik, agar manusia tidak hanya 
mementingkan ego tersendiri. Menurut Sumirat dan Suryana (2014) Seorang motivator atau innovator pendidikan bisa memanfaatkan persuasi pendidikan dengan menampilkan konsep-konsep baru pendidikan untuk bisa dilaksanakan oleh pelaksana pendidikan.

Dari salah satu contoh kutipan motivasi Merry Riana dan kaitannya dengan teori dapat dikatakan bahwa dalam motivasi Merry Riana terdapat jenis persuasif pendidikan.

Selain jenis motivasi pendidikan, dalam kumpulan motivasi Merry Riana juga terdapat jenis persuasif propaganda. Menurut teori yang disampaikan oleh Sumirat dan Suryana (2014) menyatakan objek yang disampaikan dalam persuasi propaganda adalah informasi. Tentunya tujuan persuasi tidak hanya berhenti pada penyebaran informasi saja. Lebih dari itu, dengan informasi diharapkan pembaca mau dan sadar untuk berbuat sesuatu. Berikut adalah salah satu contoh motivasi yang berjenis persuasi propaganda.

"PERLIHATKAN KEMAMPUAN KITA, BUKAN HANYA LEWAT KATA-KATA DAN JANJI-JANJI SAJA, TAPI JUGA MELALUI HASIL TINDAKAN NYATA"

Kutipan motivasi di atas merupakan motivasi yang mengandung jenis persuasi propaganda. Menurut Sumirat dan Suryana (2014) persuasi propaganda sering dipakai dalam kegiatan kampanye. Isi kampanye biasanya berupa informasi dan ajakan. Tujuan akhir dari kampanye adalah agar pembaca menuruti isi ajakan kampanye tersebut. Selebaran yang berisi informasi tentang situasi tertentu yang disertai ajakan berbuat sesuatu adalah contoh persuasi propaganda. Kutipan di atas merupakan ajakan untuk memperlihatkan kemampuan dengan nyata, motivasi tersebut menuntut atau mengajak agar secara langsung melakukannya.

Dari salah satu contoh kutipan motivasi Merry Riana dan kaitannya dengan teori dapat dikatakan bahwa dalam motivasi Merry Riana terdapat jenis persuasif propaganda.

(2) Kaidah kebahasaan persuasif yang digunakan pada kumpulan motivasi Merry Riana adalah menggunakan kaidah kebahasaan kata penghubung argumentatif, memakai kata bujukan, dan memakai kata kerja imperatif. Dari ketiga kaidah kebahasaan tersebut kaidah kebahasaan kata penghubung argumentatif yang lebih banyak terdapat pada kutipan motivasi Merry Riana. Kutipan motivasi
Merry Riana lebih banyak terdapat kaidah kebahasaan kata penghubung argumentatif karena dalam kutipan motivasi Merry Riana terdapat banyak kata penghubung argumentatif yaitu jika, karena, dengan demikian, sebab, akibatknya, dan oleh karena itu. Berikut adalah salah satu contoh kutipan motiasi Merry Riana yang menggunakan kata penghubung argumentatif.

"SESULIT APAPUN SITUASI KAMU
PADA SAAT INI, SEBERAT APAPUN
COBAAN ITU. SADARLAH, SELAMA KAMU
MASIH HIDUP, ITU ARTINYA TUHAN MASIH
SAYANG SAMA KAMU.
BERTERIMAKASIHLAH, KARENA TIDAK
SEMUA ORANG DIBERI KESEMPATAN ITU".

kaidah kutipan motivasi di atas mengandung argumentatif, hal tersebut ditunjukkan oleh kata karena pada kutipan di atas. Menurut Suparno dan Yunus (2008) kata penghubung argumentatif adalah kata penghubung yang menandakan hubungan alasan.

Dari salah satu contoh kutipan motivasi Merry Riana dan kaitannya dengan teori dapat dikatakan bahwa dalam motivasi Merry Riana terdapat kaidah kebahasaan kata penghubung argumentatif.

Selain kaidah kebahasaan kata penghubung argumentatif, dalam motivasi Merry Riana juga terdapat kaidah kebahasaan kata kerja imperatif dan kata bujukan. Berikut dua contoh kutipan motivasi Merry Riana yang mengandung kata kerja imperatif dan kata bujukan.

"JANGAN HANYA BUAT RESOLUSI, TAPI JUGA NIAT UNTUK MENJALANINYA. KAMU HARUSNYA SEPERTI PERANGKO, YANG NEMPEL TERUS SAMPAI DI TUJUAN. KAMU HARUSNYA MASA BODO, LUPAKAN SEMUA KETAKUTAN DAN KEKHAWATIRAN"

"PERLIHATKAN KEMAMPUAN KITA, BUKAN HANYA LEWAT KATA-KATA DAN JANJI-JANJI SAJA, TAPI JUGA MELALUI HASIL TINDAKAN NYATA"

Kutipan di atas merupakan kutipan
motivasi yang mengandung kaidah kebahasaan kata bujukan dan kata kerja imperatif. Menurut Suparno dan Yunus (2008) kata bujukan ditandai oleh kata harus, penting, dan pantas. Kata bujukan di atas ditunjukan oleh kata harusnya. Sedangkan kata kerja imperatif menurut Suparno dan Yunus (2008) adalah kata kerja yang digunakan untuk 
memberi perintah, larangan dan instruksi. Pada kutipan motivasi di atas terlihat bahwa kata-kata yang digunakan mengandung makna untuk memerintah dan memberikan instruksi untuk memperlihatkan kemampuan secara nyata.

Dari salah dua contoh kutipan motivasi Merry Riana dan kaitannya dengan teori dapat dikatakan bahwa dalam motivasi Merry Riana terdapat kaidah kebahasaan kata kerja imperatif dan kata bujukan.

\section{PENUTUP}

Berdasarkan permasalahan yang diajukan, jenis persuasif yang digunakan dalam kumpulan motivasi Merry Riana dan kaidah kebahasaan yang digunakan dalam kumpulan motivasi Merry Riana dapat disimpulkan sebagai berikut.

Jenis Persuasif yang digunakan dalam kumpulan motivasi Merry Riana adalah jenis persuasif propaganda dan jenis persuasif pendidikan. Dari empat puluh data yang dianalisis, jenis persuasif propaganda paling banyak ditemukan dalam motivasi Merry Riana. Hal tersebut disebabkan oleh kata-kata yang digunakan dalam motivasi Merry Riana bersifat memberikan informasi sejenis kampanye agar pembaca mau dan sadar untuk berbuat sesuatu. Sedangkan jenis persuasi pendidikan hanya sedikit yang ditemukan.

Kaidah kebahasaan yang digunakan dalam kumpulan motivasi Merry Riana ada tiga yaitu, kata bujukan, kata kerja imperatif, dan kata penghubung argumentatif. Dari data yang telah dianalisis kaidah kebahasaan yang sering digunakan adalah kaidah kebahasaan kata penghubung argumentatif. Hal tersebut disebabkan oleh kaidah kebahasaan argumentatif kata penghubung yang menandakan hubungan alasan. Pada kumpulan motivasi Merry Riana banyak ditemukan kata-kata yang menandakan hubungan alasan, contohnya kata karena yang digunakan pada sebagian kutipan motivasi Merry Riana.

\section{DAFTAR PUSTAKA}

A.M. Sardiman, 2007, Interaksi dan Motivasi Belajar Mengajar: Bandung, Rajawali Pers.

Andersen., Kenneth E., 2000, Introduction to Communication Theory and Practice, Philippines: Cumming Publ Company.
Aunurrahman. 2011. Belajar dan Pembelajaran. Bandung: Alfabeta.

Baharuddin. 2008. Teori Belajar dan Pembelajaran. Yogyakarta: Ar-Ruzz Media.

Bettinghaus, Erwin P. 1973. Persuasive Communication. Holt, Rinehart, and Winston. New York.

Budiyanto, Dwi. 2014. "Aspek Persuasif dalam Bahasa Iklan Partai Politik". Jurnal Litera. Vol.13, No.1, April 2014. Yogyakarta: Universitas Negeri Yogyakarta.

Devito, Joseph A. 2011.“Komunikasi Antar Manusia”. Tanggerang: Kharisma.

Djajasudarma, T Fatimah. 1994. Wacana Pemahaman dan Hubungan Antarunsur. Bandung: PT Eresco.

Effendy, Onong Uchjana. 2011. IImu Komunikasi. Teori dan Praktek, Bandung, Rosda.

Emda, Amna. 2017. Kedudukan Motivasi Belajar Siswa Dalam Pembelajaran. Lantanida Journal, Vol. 5 No. 2 Hal. 93-196. Tersedia Pada: https://jurnal.arraniry.ac.id/index.php/lantanida/article/ download/2838/2064.

Fauziah, Amni, Asih Rosnaningsih, Samsul Azhar. Hubungan Antara Motivasi Belajar dengan Minat Belajar Siswa Kelas IV SDN Poris Gaga 05 Kota Tangerang. Jurnal JPSD Vol. 4 No. 1 Hal. 47-53. Tersedia Pada: http://journal.uad.ac.id/index.php/JPS D/article/download/9594/4654.

Hamalik, Oemar. 2011. Kurikulum dan Pembelajaran. Jakarta: Bumi Aksara.

Saptono, Yohanes Joko. 2016. Motivasi Dan Keberhasilan Belajar Siswa. Jurnal Pendidikan Agama Kristen Regula Fidei Vol. 1 No. 1 Hal. 189-212. Tersedia Pada: http://ejournal.uki.ac.id/index.php/regul afidei/article/view/Motivation\%3B\%20S uccess $\% 3 \mathrm{~B} \% 20$ Learning. 
Sugiyono. 2012. Memahami Penelitian Kualitatif. Bandung: Alfabeta.

Sumirat \& Suryana, Soleh \& Asep. 2014. Komunikasi Persuasif. Banten :Universitas Terbuka.

Waruwu, Fotuho. 2017. Analisis Tentang Pengaruh Motivasi Intrinsik dan Motivasi Ekstrinsik terhadap Kinerja Karyawan Studi Kasus: di Rumah Sakit Rajawali dan Stikes Rajawali Bandung (Yayasan Kemanusian Bandung Indonesia). Jurnal Manajemen Maranatha, Volume 16, Nomor 2, Hal. 133-212. Tersedia Pada:

http://journal.maranatha.edu/jmm. 